ISSN: 0514-7336

DOI: http://dx.doi.org/10.14201/zephyrus2015765776

\title{
LA CONSTRUCCIÓN ANULAR Y EL ENCLOS DE VENTOSIÑOS (COESES, LUGO). ESTUDIO PRELIMINAR DE UN CONJUNTO DEL BRONCE FINAL
}

\section{The ringwork and the Ventosiños enclos (Coeses, Lugo). Preliminary study of an Late Bronze ensemble}

\author{
Diego Piay Augusto, Juan A. Cano Pan y Juan Naveiro López \\ *Arqueoloxía do Noroeste SLU. Plaza Maestro Rodrigo, 7. 15173 Oleiros. Correo-e: diego.piay@arquenor.net; \\ juan.cano@arquenor.net; juan.naveiro@arquenor.net
}

Recepción: 24/1/2014; Revisión: 6/02/2015; Aceptación: 19/09/2015

BIBLID [0514-7336 (2015) LXXVI, julio-diciembre; 57-76]

\begin{abstract}
Resumen: Durante las obras de construcción de la autovía A-54 de Lugo a Santiago de Compostela, se documentó en el lugar de Ventosiños, en la parroquia lucense de Coeses, un tipo de estructura ignota hasta la fecha dentro de la Prehistoria gallega. Se trata de una construcción de morfología anular, erigida con sedimento y elementos líticos, que delimita una superficie interna en la que se localizaron diversas fosas con restos cerámicos y líticos en su interior, y recipientes in situ. Además, al $\mathrm{N}$ de dicha estructura, se localizó un cercado o enclos que envuelve un área aún mayor, en la que se documentaron improntas de diferentes morfologías y también fosas, algunas de las cuales presentaban en su interior discos perforados y recipientes.

El presente análisis tiene como finalidad exponer de forma sucinta los datos preliminares de las actuaciones arqueológicas realizadas en todo el conjunto, dado que el yacimiento se encuentra todavía en fase de estudio.

Palabras clave: Prehistoria reciente; Galicia; fosas; discos perforados; vasos troncocónicos; contexto ceremonial.
\end{abstract}

AвSTRACt: During the construction works of the A-54 from Lugo to Santiago de Compostela highway, a structure was documented in Ventosiños place, in the parish of Coeses (Lugo), of a kind so far unknown in the context of Galician Prehistory. It was a ring-shaped construction, built with sediment and stone elements, enclosing an inner area in which various pits with lithic and ceramic remains and in situ placed vessels inside were found. In addition, North of this structure, a fence or enclos was located, enveloping an even larger area, in which impressions of diferent morphologies and pits were found. Some of them had perforated disks and in situ placed vessels inside.

Present analysis is intended to briefly summarize the preliminary data obtained from the archaeological works carried out in the whole ensemble, since the site is still under study.

Key words: Late Prehistory; Galicia; pits; perforated disks; frustum vessel; ceremonial context.

(c) Universidad de Salamanca

Zephyrus, LXXVI, julio-diciembre 2015, 57-76 


\section{Introducción}

Las intervenciones arqueológicas a las que haremos referencia se desarrollaron en el lugar de Ventosiños (Coeses, Lugo) entre 2011 y 2013, en el marco de la construcción de la autovía A-54, que en el futuro unirá las localidades de Lugo y Santiago de Compostela. Como a menudo ocurre en las actuaciones arqueológicas 'de urgencia', las intervenciones se desarrollaron de forma discontinua y progresiva, en función de los resultados que se iban obteniendo durante el transcurso de los trabajos ${ }^{1}$.

El área arqueológica, que ocupa un espacio al que los lugareños se refieren con el microtopónimo 'a chousa do castro', se encuentra al E del río Miño, a una distancia de $1,3 \mathrm{~km}$ (Fig. 1). Un pequeño curso de agua heredero del Rego de Vilalvite delimita el espacio excavado por su parte occidental, dirigiéndose después hacia el $\mathrm{N}$, hasta bordear el Castro de Ventosiños, que se localiza a apenas $50 \mathrm{~m}$ del límite septentrional del área excavada. La superficie intervenida -en una situación prominente en relación con el territorio circundante- se ubica en una dorsal con orientación SO-NE, que se extiende desde el límite meridional del área excavada hasta el Castro de Ventosińos. Las coordenadas UTM de referencia son $\mathrm{x}$ : 619334.600, y: 4757121.700, z: 480 m. El área total de excavación en el Sector I, espacio al que se refiere el presente trabajo, ascendió a $8.965 \mathrm{~m}^{2}$.

Desde el punto de vista geológico, se trata de un espacio dominado por micaesquistos paleozoicos, muy ricos en moscovita y cuarzo, y que presentan una esquistosidad muy marcada. Su aspecto es brillante, de color gris o amarillento, y puntualmente alternan niveles cuarcíticos y de gneises pelíticos con granate. En el área excavada aparecen recubiertos de depósitos coluvio-aluviales de escasa entidad, que presentan niveles de cantos, limos y arcillas.

En el momento en que se iniciaron las intervenciones arqueológicas, la superficie de excavación se enmarcaba dentro de un área dedicada a repoblación, con un pequeño espacio, ubicado en la parte oriental y nororiental, dedicado a cultivo.

1 No nos detendremos en el presente estudio en la descripción de las diferentes fases ejecutadas, dado que nuestro objetivo es ofrecer una visión de conjunto de los datos extraídos en el curso de las intervenciones y exponer las conclusiones preliminares a las que nos han conducido las investigaciones realizadas hasta la fecha.
Como ya hemos señalado, se trató de una intervención de urgencia, realizada en unos márgenes de tiempo muy reducidos, por lo cual nuestros objetivos fueron limitados y restan pendientes otros de indudable interés. Debe tenerse en cuenta que no se trató de un proyecto de investigación; ante la pérdida inevitable de parte del yacimiento se intentaron registrar, con metodología científica y de la forma más rigurosa posible, las características principales de las estructuras y los restos materiales presentes en el área de excavación.

\section{Descripción de los restos localizados}

La mayor parte de las estructuras documentadas en el curso de las intervenciones arqueológicas se concentran en dos espacios muy concretos. El primero de ellos, ubicado en la parte meridional del área excavada, se define por la presencia de una estructura que en adelante denominaremos 'construcción anular', e incluye también la superficie delimitada por ésta. El segundo espacio, al norte del primero, y fuera por tanto de la superficie delimitada por la construcción anular, se extiende hacia el $\mathrm{N}$ hasta alcanzar un enclos o cercado que discurre concéntrico a la construcción anular, y que marca el límite de este segundo espacio. Más allá del enclos los restos arqueológicos aparecen más diseminados y las estructuras disminuyen considerablemente, por lo que el presente estudio se centrará fundamentalmente en los dos espacios principales.

\subsection{La construcción anular y su espacio interno}

\subsubsection{La construcción anular}

Es, sin duda, el elemento más sobresaliente documentado en el transcurso de las intervenciones realizadas, dada su singularidad en el panorama arqueológico gallego. Se trata de un conjunto de carácter monumental, definido por una masa sedimentaria y lítica delimitada en su cara externa e interna por elementos pétreos. A pesar de que la zona meridional de la construcción anular [CA] ha desaparecido, debido

2 La asignación de esta denominación no es arbitraria; obedece a las similitudes detectadas entre la construcción localizada en Ventosiños y un tipo de estructura ya conocido en Gran Bretańa como ringwork, cf. infra, p. 75. 

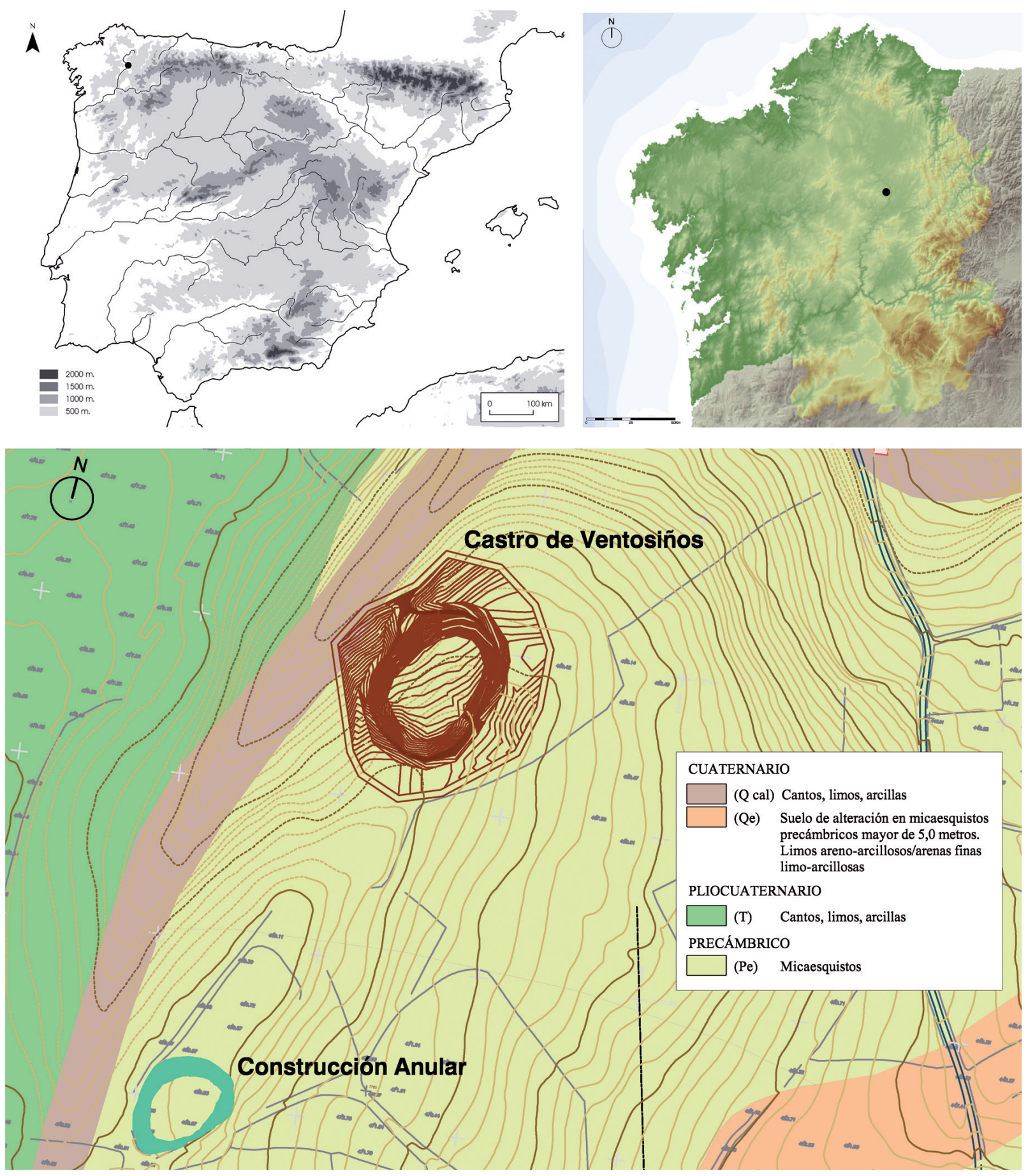

FIG. 1. Ubicación del yacimiento de Ventosiños en plano hipsométrico y cartografía. 


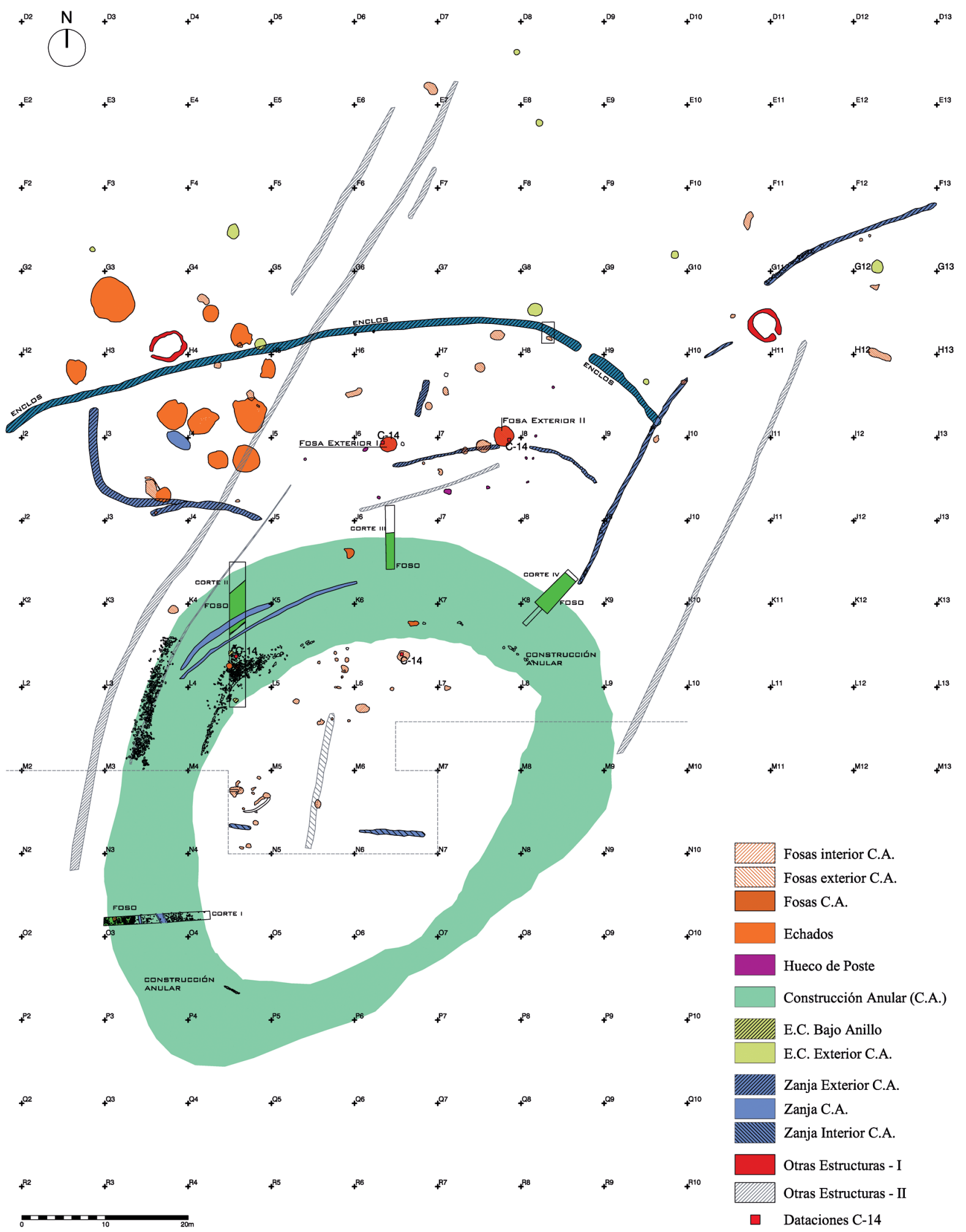

Fig. 2. Planimetría general del espacio excavado. 


\begin{tabular}{|c|c|c|c|c|c|c|c|c|c|}
\hline \multirow{2}{*}{ ESTRUCTURA } & \multicolumn{4}{|c|}{ MORFOLOGÍA } & \multirow{2}{*}{ UR } & \multicolumn{3}{|c|}{ DIMENSIONES } & \multirow{2}{*}{ UBICACIÓN } \\
\hline & Planta & Perfil & BASE & Paredes & & Longitud & Anchura & Profundidad & \\
\hline FOSA EXTERIOR I & circular & 'U' & irregular & rectas & $\begin{array}{l}\text { I } 6 \\
\text { J } 6\end{array}$ & $2 \mathrm{~m}$ & $1,75 \mathrm{~m}$ & $0,80 \mathrm{~m}$ & $\begin{array}{c}\text { sup. no } \\
\text { delimitada por } \\
\text { la CA }\end{array}$ \\
\hline FOSA EXTERIOR II & circular & 'u’ & plana & rectas & $\begin{array}{l}17 \\
\text { J } 7\end{array}$ & $2,37 \mathrm{~m}$ & $2,42 \mathrm{~m}$ & $0,90 \mathrm{~m}$ & $\begin{array}{c}\text { sup. no } \\
\text { delimitada por } \\
\text { la CA }\end{array}$ \\
\hline ENCLOS & circular & 'v' & plana & oblicuas & $\begin{array}{l}\text { I } 1-4 \\
\text { H } 4-8 \\
\text { I } 8-9\end{array}$ & $85 \mathrm{~m}$ & $1,70 \mathrm{~m}$ & $0,70 \mathrm{~m}$ & $\begin{array}{c}\text { sup. no } \\
\text { delimitada por } \\
\text { la CA }\end{array}$ \\
\hline Foso & circular & 'v' & plana & oblicuas & $\begin{array}{l}\text { L } 4 / \mathrm{L} 8 \\
\mathrm{~K} 4 / \mathrm{K} 6 \\
\mathrm{~K} 8 / \text { о } 3\end{array}$ & $\begin{array}{l}\text { ¿70 m? } \\
\text { (diám.) }\end{array}$ & $5 \mathrm{~m}$ & $2 \mathrm{~m}$ & $\begin{array}{c}\text { rodeando a } \\
\text { la CA }\end{array}$ \\
\hline $\begin{array}{l}\text { CONSTRUCCIÓN } \\
\text { ANULAR } \\
\text { [CA] }\end{array}$ & circular & --- & --- & --- & $\begin{array}{c}\text { K 4/8 } \\
\text { L 3-8 } \\
\text { M 3-4 } \\
\text { M 8-9 } \\
\text { N 3-4 } \\
\text { N 7/N } 9 \\
\text { O 3-4 } \\
\text { o } 6-8 \\
\text { P 3-7 } \\
\text { Q 3-4 }\end{array}$ & 60 m (diám.) & $10 \mathrm{~m}$ & $1,5 \mathrm{~m}$ & $\begin{array}{c}\text { espacio } \\
\text { meridional del } \\
\text { área excavada }\end{array}$ \\
\hline
\end{tabular}

FIG. 3. Tabla descriptiva de las principales estructuras mencionadas en el texto.

a la existencia de un camino tradicional, es posible aseverar que el diámetro aproximado de la construcción alcanzaría unos $60 \mathrm{~m}$, englobando un espacio interno de unos $40 \mathrm{~m}$. Más adelante analizaremos la posibilidad de que la construcción anular contase al menos con un vano en la parte orientada al NE, dado que algunas evidencias detectadas en el exterior de la estructura apuntan en esta dirección ${ }^{3}$.

En la zona interna, la estructura presenta una cara vista conformada con cantos de cuarcita de buen tamaño que configuran una única hilada, cayendo después hacia el interior con una masa de tierra y ciertos elementos pétreos que pudieron formar parte de la estructura original o que quizás se desprendieron paulatinamente desde su zona más alta. En la parte externa, la construcción anular se caracteriza por la presencia de un anillo lítico que soportaba el peso de la masa sedimentaria hacia el exterior, al tiempo que la delimitaba. Este anillo es especialmente visible en la zona occidental de la estructura, la mejor conservada, siendo prácticamente inapreciable en la parte

$$
3 \text { Cf. infra, p. } 64
$$

oriental. El conjunto de masa sedimentaria y elementos pétreos alcanza aproximadamente unos $10 \mathrm{~m}$ de anchura, elevándose hasta $1,50 \mathrm{~m}$ hacia poniente, donde menos degradada está la construcción anular. El resto de la estructura se encuentra más desparramada, siendo casi imperceptible en el NE y E, donde la base de la construcción anular se confunde y mimetiza con la pendiente existente, por lo que resulta ardua tarea discernir el límite entre una y otra.

A fin de conocer la morfología de la construcción anular se realizaron cuatro cortes en esta estructura. En el corte n. ${ }^{\circ} 2$-el único que se excavó íntegramente-, ubicado en la parte norte de la construcción anular, se localizaron abundantes restos cerámicos -más de 200 fragmentos exhumados en una cata de 2 x 16 $\mathrm{m}-$. Ello indica, sin lugar a dudas, que cuando se erigió la estructura se incluyeron grandes contingentes de material desechado en el sedimento que conformaba la misma. Además, una vez extraídos los niveles pétreos y sedimentarios que configuran la construcción anular, se documentaron dos estructuras de combustión por debajo de los mismos, que quizás 
tienen que ver con un rito de carácter fundacional, aunque no pueden descartarse otras hipótesis como la existencia de una fase más antigua. La última sorpresa que reveló este corte fue el descubrimiento, soterrado bajo los restos desparramados del paramento exterior, de un foso de $5 \mathrm{~m}$ de anchura y unos $2 \mathrm{~m}$ de profundidad, con sección en ' $v$ '. El corte n. ${ }^{\circ} 4$ se realizó con la intención de confirmar la presencia del foso en otro punto del perímetro de la construcción anular, y se ubicó en su parte nororiental, zona en la que como se ha dicho la conservación de esta estructura era precaria. Las dimensiones del nuevo corte fueron de $1,70 \times 5,60 \mathrm{~m}$, documentando otro tramo de foso de $5 \mathrm{~m}$ de anchura y $2 \mathrm{~m}$ de profundidad, medidas prácticamente idénticas a las ya conocidas. Diferencias apreciables se documentaron, no obstante, en la secuencia estratigráfica. Mientras que en el primer corte todo apuntaba a una amortización intencionada del foso, señalada por la presencia de un relleno pétreo homogéneo que configuraba el paramento externo de la construcción anular al tiempo que cubría el corte del foso, en el segundo la secuencia estratigráfica era mucho más rica y sin evidencias de amortización. El corte n. 3 permitió confirmar la presencia del foso en la parte norte de la construcción anular, si bien se documentó solamente en planta; en el corte n. ${ }^{\circ} 1$ una diferente coloración del sedimento parece revelar también la presencia del foso en la parte oeste de la construcción anular. Este corte se planteó en la parte mejor conservada de la estructura, aunque desgraciadamente no fue posible completar su excavación.

La posibilidad de extraer conclusiones a partir de los cortes realizados se antoja arriesgada, máxime si tenemos en cuenta que, suponiendo que el foso rodease originalmente toda la construcción anular, la parte documentada del mismo representaría tan sólo un $6 \%$ de su perímetro total. Y no debemos olvidar que la configuración de la estructura a lo largo de su historia debió de sufrir sin duda modificaciones que pudieron afectar a zonas concretas o a todo el conjunto. Determinar todas y cada una de estas cuestiones sería sólo posible con la realización de un número elevado de cortes en el foso y en la construcción anular, que posibilitarían un conocimiento más exhaustivo de ambas estructuras. Lo que parece altamente probable es que el foso y la construcción anular se realizasen en el mismo período, aprovechando el sedimento extraído durante la construcción del foso para erigir la construcción anular.

\subsubsection{El espacio interno}

Se excavó aproximadamente un 36\% del total del área definida dentro del perímetro enmarcado por la construcción anular. La intervención en esta superficie fue extremadamente compleja dadas las condiciones de sequedad del terreno, que hicieron muy complicada la correcta detección y documentación de improntas. No obstante, se localizaron hasta 5 recipientes cerámicos in situ, ubicados en la zona anexa al paramento interno de la construcción anular, principalmente en su parte norte y noroeste. Además se localizaron un total de veintiséis fosas en las cuales, a pesar de su morfología irregular y, en muchos casos, su dudoso carácter antrópico, se localizaron restos cerámicos fragmentados y una cuenta de collar esférica de pasta vítrea. Todas las estructuras localizadas en el interior de la CA se corresponden con fosas, exceptuando una zanja con orientación N-S y una zanja con orientación E-O. Especial interés por sus dimensiones tienen los recipientes localizados en las URS $\mathrm{N} 4$ y $\mathrm{M} 4$, que aparecieron colmatados de sedimento y material pétreo. El primero de ellos se exhumó en el interior de una fosa, mientras que el segundo estaba insertado en el depósito aluvial original, sin haber documentado una fosa que lo contuviese. No obstante, para la inserción de este último recipiente debió de realizarse también una fosa, y en este caso es probable que la presunta estructura se hubiese rellenado con el mismo sedimento que hubo de extraerse para colocar el recipiente, dificultando su detección durante la excavación.

\subsection{El espacio externo}

En cuanto al área que se extiende al $\mathrm{N}$ de la construcción anular, pueden distinguirse también dos espacios claramente diferenciados cuya delimitación está señalada por la presencia de un cercado perimetral o enclos. La primera zona abarca la superficie que se extiende entre la construcción anular y el propio enclos. En cuanto a la segunda, se ubica en la parte septentrional del enclos, definiéndose su límite norte por la expropiación señalada para la ejecución de la obra pública. 

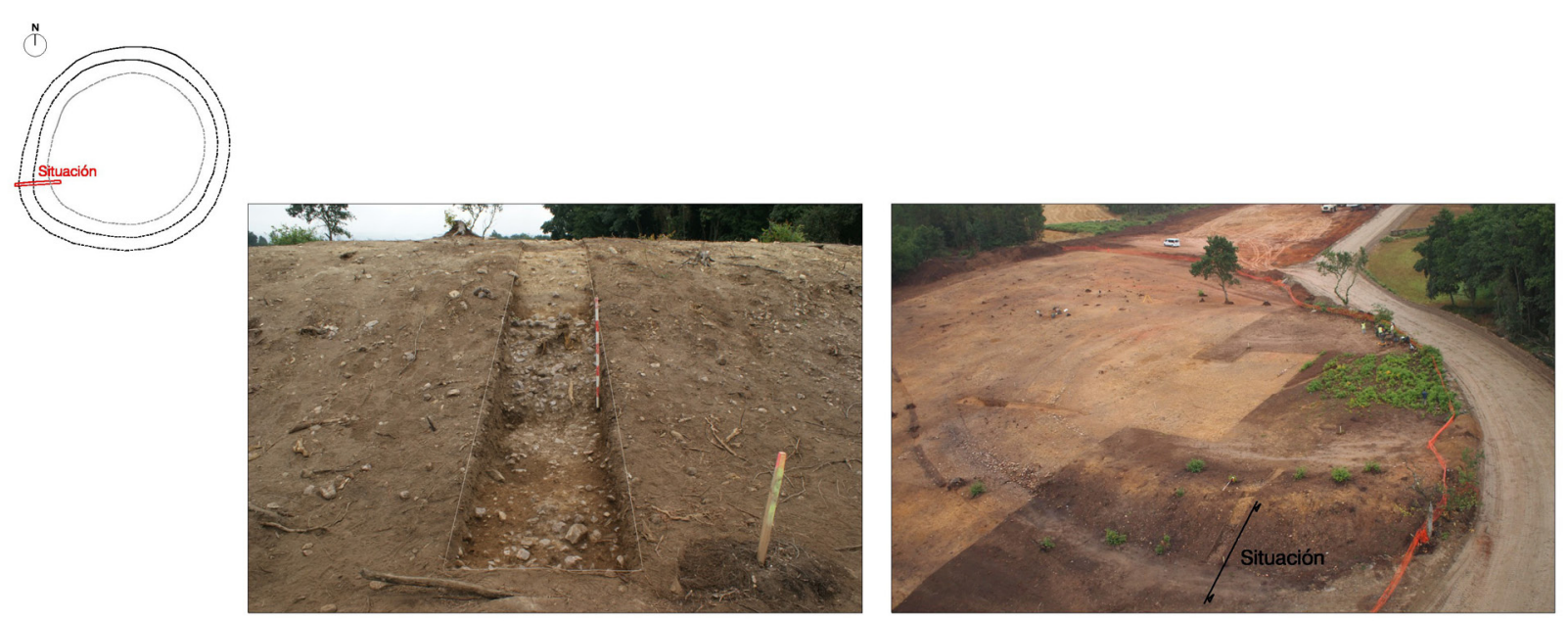

o

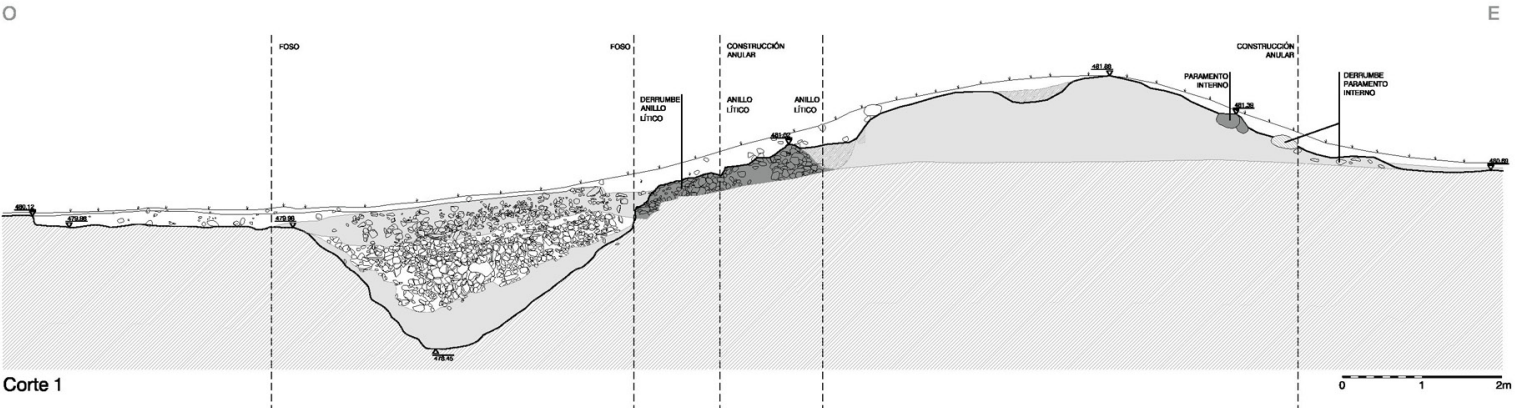

FIG. 4. Imágenes de la construcción anular y sección de la construcción anular y el foso en el corte 1.

\subsubsection{El enclos}

Se trata de una impronta de carácter lineal localizada al norte de la construcción anular, a unos $25 \mathrm{~m}$, y que discurre concéntrica a esta con orientación E-O. Su longitud aproximada es de $85 \mathrm{~m}$, extendiéndose hacia el o hasta prácticamente alcanzar el curso de agua existente, y hacia el $\mathrm{E}$ hasta llegar a una zanja con orientación SO-NE, que marca el límite de la estructura en esta zona. El enclos alcanza una longitud de $85 \mathrm{~m}$, con un ancho máximo de $1,70 \mathrm{~m}$ en su parte superior, cerrándose progresivamente hacia la base hasta completar una sección perfecta en 'v'. Su profundidad media es de $0,70 \mathrm{~m}$ en la parte más alta de la superficie excavada, descendiendo hacia las laderas este y oeste del espacio intervenido hasta los 0,33 $\mathrm{cm}$. El depósito que colmata el corte es en general homogéneo, concentrándose en algunos puntos del sedimento restos líticos - destaca la presencia de cinco discos de esquisto perforados- y cerámicos, habiendo sido localizados fragmentos de dos recipientes casi completos -depositados in situ- que han permitido reconstruir su forma. El hallazgo de restos materiales desciende significativamente en la parte occidental del enclos, siendo su presencia testimonial en los últimos $25 \mathrm{~m}$ de la estructura. No se documentaron en el corte del enclos o en su relleno evidencias que denoten la presencia de una estructura tipo empalizada o similar ${ }^{4}$.

4 En el yacimiento de Pego (Braga, Portugal) se localizó una vala perimetral datada en el Bronce final, que presenta características análogas al enclos de Ventosińos, incluyendo la presencia de recipientes prácticamente completos en su interior. En el relleno de esta estructura se localizaron además sedimentos carbonizados y piedras hincadas que según sus excavadores apuntarían a la presencia de una empalizada de madera (Sampaio, H. T. A.: A Idade do Bronze na bacia do Rio Ave (Noroeste de Portugal), tesis doctoral presentada en 2014 en Univ. Do Minho [disponible en: https://repositorium. sdum.uminho.pt/handle/1822/35559], pp. 335-336). 
Aunque en el transcurso de la intervención arqueológica no pudo determinarse la relación estratigráfica entre la construcción anular y la zanja que delimita el enclos por su parte oriental, así como de la zanja localizada en la parte hacia poniente, todo parece apuntar a que ambas estructuras se extendían hasta el foso, delimitando, en combinación con la construcción anular y el enclos, un área de $67 \mathrm{~m}$ de lado en el eje E-O y $24 \mathrm{~m}$ de lado en el eje N-s. Es precisamente en este espacio de unos $1.400 \mathrm{~m}^{2}$ donde se concentran la mayor parte de las estructuras documentadas durante las intervenciones arqueológicas. Por otra parte, existen evidencias que apuntan a la presencia de un acceso al recinto al NE del enclos, dado que este se interrumpe creando un vano de 1,50 $\mathrm{m}$. Desde esta zona y en dirección a la construcción anular, el espacio se encuentra expedito de restos materiales y de estructuras, reduciéndose además la presencia de piedras y cantos en esta zona, situación que contrasta con lo que sucede en el resto de la superficie excavada, donde la presencia de estos elementos es notable. Sí se localizaron cuatro agujeros de poste alineados hacia la construcción anular que delimitan este 'paso' por la parte oeste, y una zanja circular concéntrica a la construcción anular y al enclos. Más al $s$, ya en la construcción anular, aunque no se aprecia una ruptura en la masa sedimentaria, sí es cierto que en esta misma dirección el paramento interno se interrumpe y el paramento externo no está presente -hay que tener en cuenta que esta zona de la construcción anular se encuentra mucho más degradada que la parte occidental-.

\subsubsection{Estructuras localizadas entre la construcción anular y el enclos}

Como se ha dicho, en el área configurada por la presencia del enclos al $\mathrm{N}$, la construcción anular al $\mathrm{s}$ y las zanjas ubicadas al $\mathrm{E}$ y al $\mathrm{O}$, se documentaron la gran mayoría de los restos arqueológicos. La zanja ubicada al o de la construcción anular tiene -al igual que el enclos- sección en ' $v$ ', si bien la presencia de material en el sedimento que la colmata es cuantitativamente inferior. Cuenta con una potencia de 0,30 m y una anchura en la parte superior de $1 \mathrm{~m}$. En cuanto a la zanja ubicada al E, se pudo verificar que el enclos se adosa a esta estructura, por lo que puede afirmarse que esta ya existía cuando se delimitó la superficie ubicada al $\mathrm{N}$ de la construcción anular con el enclos, aunque es imposible precisar el intervalo cronológico que medió entre la realización de ambas estructuras. La zanja se desarrolla durante $27 \mathrm{~m}$ con una ligera curvatura, para a continuación interrumpirse durante $15 \mathrm{~m}$, retomando después su recorrido nuevamente durante 23 m hasta su final. Su sección es en 'u', y el corte está colmatado con bolos cuarcíticos y sedimento, alcanzando una profundidad de 0,20 $\mathrm{m}$ y $0,60 \mathrm{~m}$ de anchura. Durante la excavación del relleno de esta zanja se localizaron algunos restos cerámicos.

- Fosas: se localizó un total de 32 fosas antrópicas en el exterior de la construcción anular. De entre ellas destacan sobre las demás la Fosa Exterior I, localizada entre las uRs J6 e i6, y la Fosa Exterior II, documentada entre las URS J7 e I7. La primera de ellas, de planta casi circular, tiene una longitud de 2 $\mathrm{m}$ en su eje E-O y de $1,75 \mathrm{~m}$ en su eje $\mathrm{N}-\mathrm{s}$, alcanzando una profundidad de $0,80 \mathrm{~m}$. La segunda -también de planta prácticamente circular- es ligeramente mayor, alcanzando $2,37 \mathrm{~m}$ en su eje E-O y $2,42 \mathrm{~m}$ en su eje N-S. Su profundidad máxima es también mayor que la de la fosa anteriormente descrita, llegando hasta $0,90 \mathrm{~m}$. La secuencia estratigráfica documentada en ambas fosas era muy similar: a un nivel pétreo superficial con presencia de cantos de cuarcita rubefactados, subyacían diferentes estratos de tierra, hasta alcanzar un nuevo nivel pétreo conformado principalmente por lajas de esquisto dispuestas horizontalmente. Bajo este nivel subyacían de nuevo rellenos de tierra hasta alcanzar la base de la fosa. Todos los estratos de relleno presentaban abundantes restos cerámicos y restos de recipientes completos o semicompletos, pero las mayores concentraciones se documentaron bajo los niveles pétreos. En el interior de dichas fosas se localizaron además discos de esquisto circulares o de tendencia circular con perforación central bitroncocónica.

- Agujeros de poste: se identificó un total de 13 agujeros de poste ubicados en las URS J6, J7, J8 e I8, con diámetros oscilantes entre 20 y $30 \mathrm{~cm}$ y una profundidad no superior a $20 \mathrm{~cm}$. La mayoría de ellos aparecen con un elemento pétreo asociado. En general todos presentan sedimentos homogéneos y estériles con coloraciones bastante similares. El estudio detallado de la planimetría permite detectar alineaciones entre ellos, como la presente entre las 
URS J8-IO, con 4 postes alineados en dirección N-S, o entre las URS J6-J8, con orientación E-O. La presencia de agujeros de poste y estructuras lineales permite postular la existencia de delimitaciones en madera que definirían espacios diferenciados en el área que se extiende entre la construcción anular y el enclos.

- Zanjas: en la UR J8 se localizó una zanja con orientación O-SE, de tendencia circular, que discurre concéntrica al enclos. Su límite hacia el o nos es conocido, mientras que en dirección e la zanja continúa en dirección a la construcción anular, sin haber podido documentar su límite en esa zona. Probablemente esta estructura

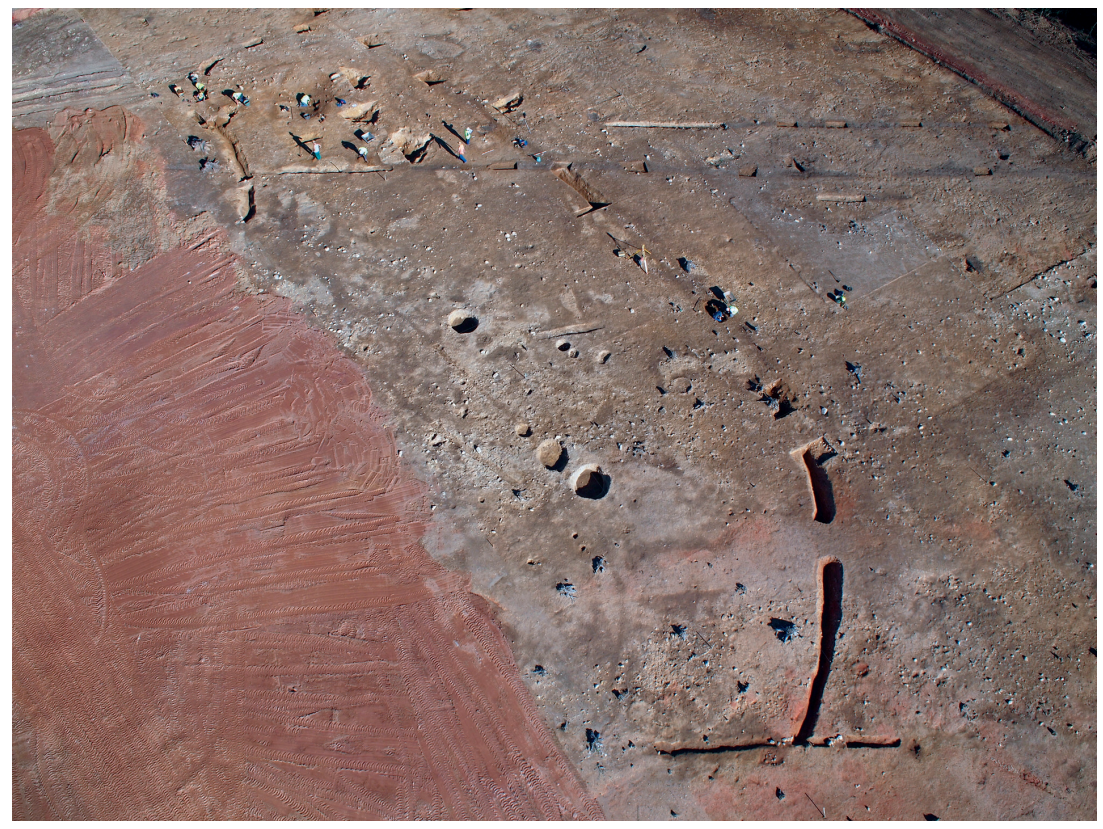

FIG. 5. Vista panorámica del enclos desde el NO. se adosa a la zanja que -hacia el E- delimita el espacio ubicado entre el enclos y la construcción anular. Cuenta con una anchura de $40 \mathrm{~cm}$ y una profundidad máxima de $10 \mathrm{~cm}$. El tramo localizado se excavó en su totalidad.

- Echados de sedimento: en la parte oeste de la zona que se extiende entre el enclos y la construcción anular, se documentaron una serie de estructuras de morfología más o menos circular, definidas en planta por la presencia de depósitos que se alzan levemente con respecto al terreno circundante. A pesar de que las dimensiones y morfología pueden variar entre todos los casos documentados, lo cierto es que sus características en común permiten analizar estas estructuras de forma conjunta. Se trata de fosas excavadas en el depósito aluvial original, que presentan un sedimento orgánico que se documenta en todo el borde de la estructura y que desciende hasta la base de la misma, cubierto después por un depósito de sustrato en proceso de alteración que cubre totalmente la fosa e incluso se eleva por encima del borde de la misma formando un pequeño cúmulo térreo. Se localizaron un total de siete estructuras que responden a estas características en el espacio existente entre el enclos y la construcción anular, todas ellas concentradas en la mitad occidental. Aunque excavadas todas

íntegramente, en ninguna de estas fosas se localizaron restos materiales. Los datos disponibles no permiten avanzar una hipótesis plausible acerca de la función de estas estructuras, más allá de señalar la voluntad de sellar estas fosas con depósitos de tono amarillento -elemento que las identifica- cuya presencia prominente favorece su visualización.

\subsubsection{Estructuras localizadas al $\mathrm{N}$ del enclos}

$\mathrm{Al} \mathrm{N}$ del enclos se excavó un área total de $4.364 \mathrm{~m}^{2}$. Esta superficie estaba delimitada por el propio enclos al s y el límite de la expropiación para la obra pública al N. Hacia el e y el o los límites de la excavación estaban definidos por el área de cautela arqueológica. En esta zona, el número de estructuras documentadas es significativamente menor al guarismo documentado en las zonas analizadas anteriormente. También se aprecia una disminución notable del material arqueológico.

- Estructuras de combustión: destaca la presencia de nueve estructuras de combustión en el exterior del enclos, hacia el N; máxime si tenemos en cuenta que al s del enclos solamente se localizaron dos estructuras 


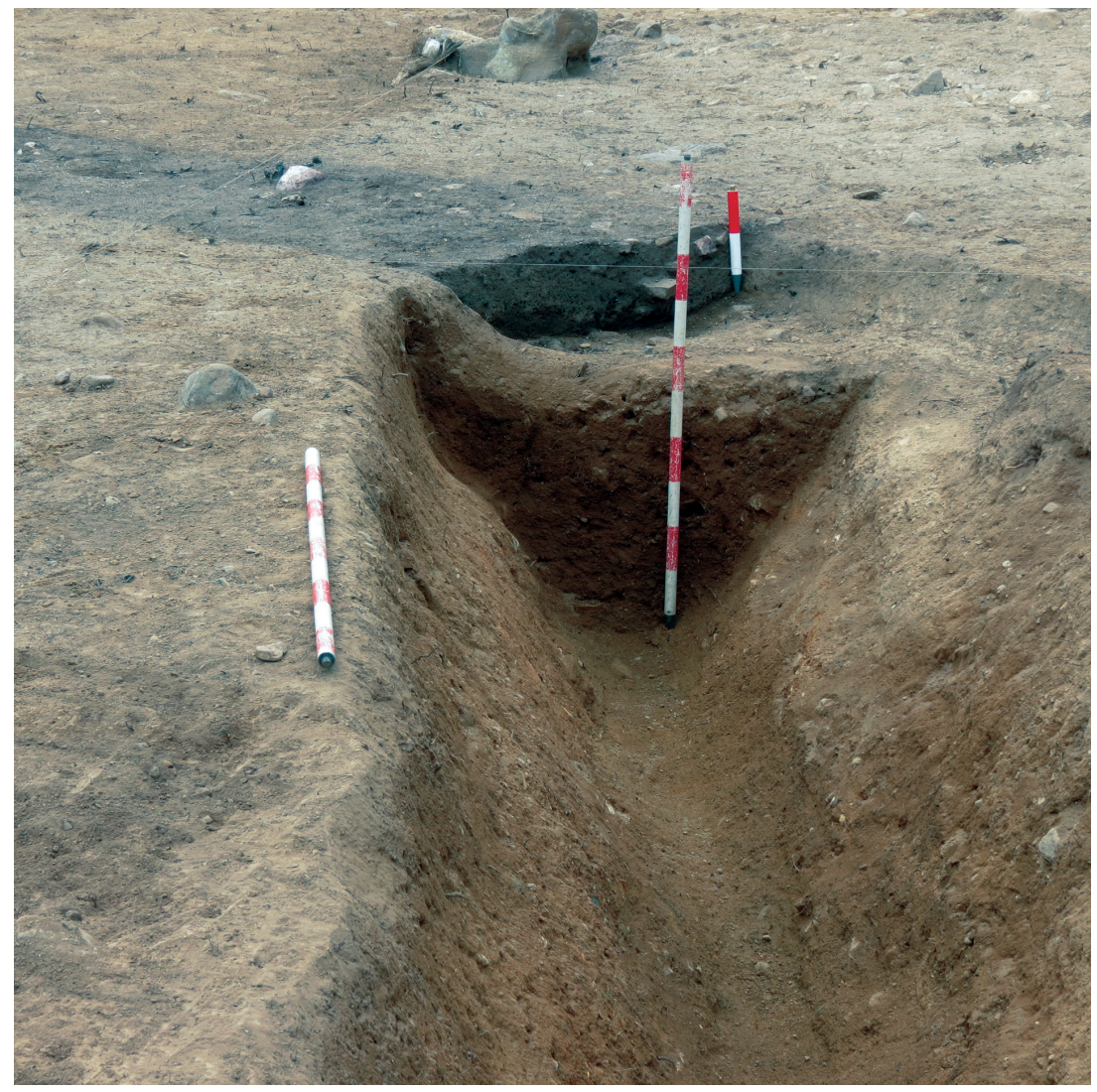

FIG. 6. Detalle de una sección del enclos y zanja superpuesta.

construcción anular y al $s$ del enclos, y que actuaban como límite $\mathrm{E}$ y o de dicho espacio ${ }^{6}$, se documentaron tres zanjas con orientación SO-NE, paralelas entre sí, y que se superponen e incluso cortan a algunas de las estructuras situadas entre la construcción anular y el enclos, y también a este último (UR H5). La estratigrafía evidencia que estas zanjas longitudinales son posteriores al resto de las estructuras documentadas, si bien es difícil precisar con exactitud su época de realización, más aún si tenemos en cuenta la escasez de materiales localizados en los depósitos que rellenan estas estructuras, así como la información que estos nos ofrecen. No obstante, la presencia de elementos vegetales no degradados en el interior de los depósitos hace pensar en una colmatación reciente, haciendo muy probable que las zanjas fuesen excavadas en época histórica ${ }^{7}$. Otro factor a tener en cuenta en apoyo de esta aseveración es

de combustión, que hemos analizado anteriormente ${ }^{5}$. A pesar de las diferencias morfológicas existentes entre ellas, se trata en todos los casos de fosas excavadas en el depósito aluvial original, que presentan en su parte superior un nivel de cuarcitas de diferentes tamaños y morfología irregular, muchas de ellas fracturadas por su exposición al fuego, y un estrato más o menos carbonizado por debajo del mismo y hasta la base. Las dimensiones son variables alcanzando la de mayor tamaño $1,75 \mathrm{~m}$ de diámetro y $0,70 \mathrm{~m}$ la menor. En cuanto a la profundidad de las fosas, oscila entre 10 y $30 \mathrm{~cm}$. De forma excepcional, en alguna de ellas se localizaron restos cerámicos y/o líticos.

- Zanjas: aparte de las estructuras ya analizadas a la hora de definir el espacio localizado al $\mathrm{N}$ de la

5 Se trata de las dos estructuras localizadas bajo los sedimentos que configuran la construcción anular, vid. supra apartado 2.1.1. el predominio evidente de la línea curva entre las estructuras lineales documentadas adscribibles a época prehistórica, en clara contraposición con las tres zanjas analizadas, totalmente rectilíneas.

- Otras estructuras: en el espacio que se extiende al norte del enclos se documentaron además otras estructuras. Entre ellas destaca la presencia, en la parte occidental del espacio excavado, de echados de sedimento como los ya descritos anteriormente ${ }^{8}$. En la parte oriental de la excavación y a menos de $1 \mathrm{~m}$ del enclos se localizó una impronta con forma de herradura, definida por un sedimento orgánico de color

6 Cf. supra epígrafe 2.2.2.

En la UR OI, a 15 m de la construcción anular, se halló en superficie una moneda de Isabel II, acuñada en 1868, pero no es posible relacionar la construcción de estas estructuras con esa cronología.

8 Cf. supra apartado 2.2.2. 
marrón oscuro amarillento. Sus dimensiones eran 3,60 $\mathrm{m}$ eje $\mathrm{N}-\mathrm{S}$ y $4,45 \mathrm{~m}$ eje E-O. El corte de la estructura es ligeramente cóncavo e irregular, con una profundidad que oscila entre 0,20 y $0,46 \mathrm{~m}$. No se documentaron restos materiales en el sedimento que colmataba el corte. Una estructura de similares características se documentó también al noroeste del enclos. También se documentó una estructura de enorme interés y difícil interpretación en la parte oriental del espacio excavado, a una distancia considerable de los demás restos exhumados. Se trata de una fosa de planta rectangular, excavada en el sustrato micaesquistoso, que cuenta con unas dimensiones de $2,94 \mathrm{~m}$ en su eje SE-NO y $0,77 \mathrm{~m}$ en su eje so-NE, con una profundidad de casi $2 \mathrm{~m}$. El interior de la estructura estaba colmatado por un depósito pétreo conformado por cantos de cuarcita de diversos tamaños $-32 \times 22 \times 13 \mathrm{~cm} ; 28 \times$ $18 \times 14 \mathrm{~cm} ; 24 \times 18 \times 16 \mathrm{~cm}$, etc. $-\mathrm{y}$ alguna losa de esquisto $-35 \times 23 \times 4 \mathrm{~cm}-$. Además se exhumaron diversos leńos carbonizados, concentrados principalmente en la parte sureste de la estructura. No se localizaron restos materiales en los sedimentos que rellenaban la fosa.

\section{Restos materiales}

Durante las campañas de excavación realizadas se completó un total de 1.946 números de registro, correspondiéndose la mayor parte de estos con restos cerámicos, seguidos de los liticos, elementos metálicos, dos cuentas realizadas en pasta vítrea, un colgante de vidrio y una moneda.

De forma general, puede afirmarse que la distribución de los restos materiales dentro del área excava$\mathrm{da}$-excluyendo las estructuras, donde se exhumaron abundantes restos cerámicos y líticos- permite confirmar la existencia de concentraciones significativas en tres zonas principales: la construcción anular y su espacio interno, la parte oriental del enclos y las fosas localizadas entre el enclos y la construcción anular, en concreto las ubicadas en las URS I6-I7 y J6-J7. Tan importantes como las presencias son las ausencias, y por ello es preciso señalar la nimiedad de restos materiales documentados al norte del enclos, más aún si tenemos en cuenta la extensión del área excavada.

\subsection{Restos cerámicos}

El conjunto cerámico recuperado es relativamente abundante si se compara con la superficie excavada, aunque su proporción aumenta al relacionarlo con las estructuras identificadas -construcción anular, fosas y enclos-, donde se concentran los hallazgos. 


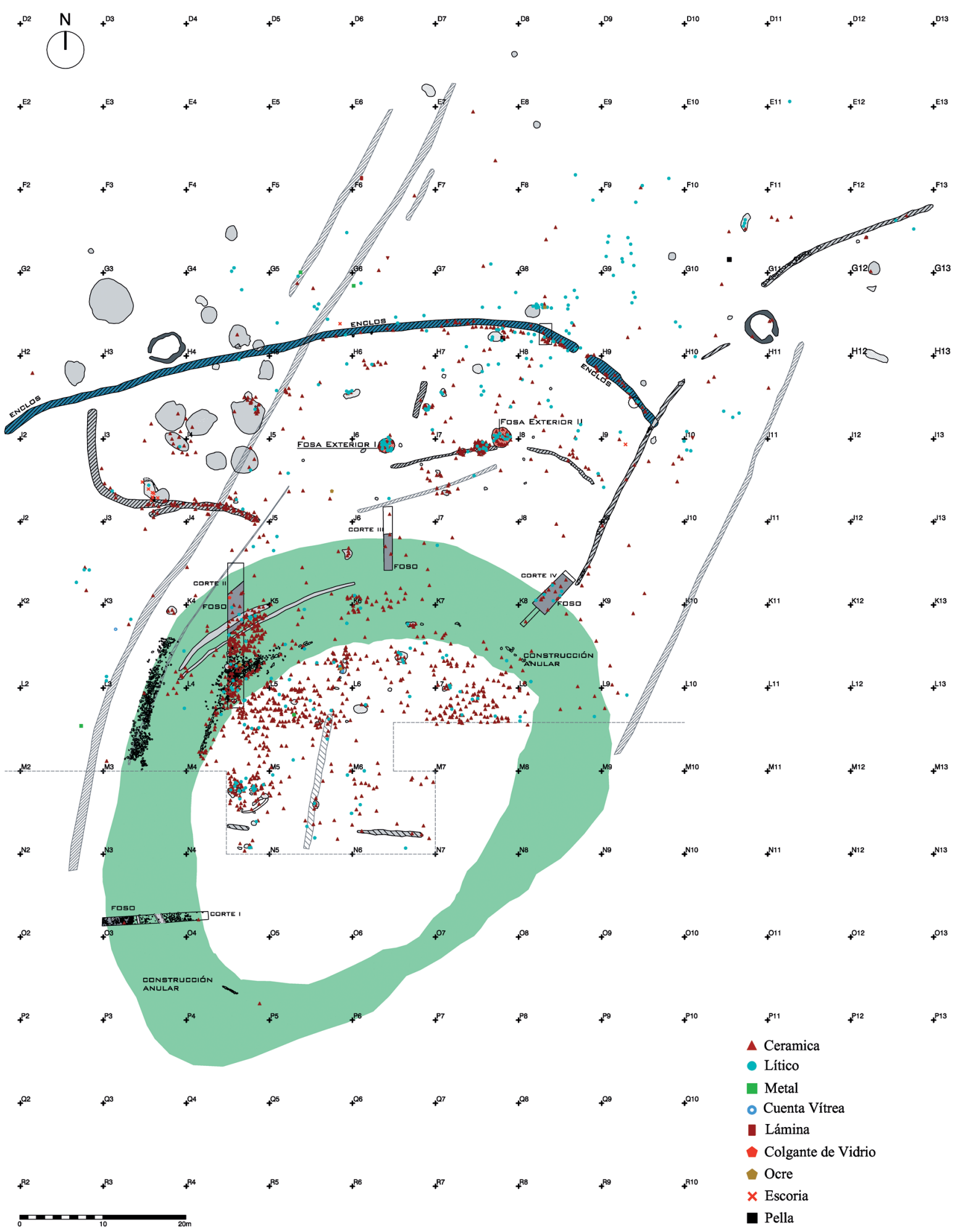

FIG. 8. Distribución de los restos materiales exhumados. 
Con un repertorio limitado de formas (Fig. 9), las piezas presentan cierta diversidad de producciones y fábricas, con diferencias tecnológicas en cuanto a modelado, cocción y acabados, dentro de un arcaísmo evidente. Los ejemplares decorados son muy escasos y prácticamente se limitan a un nivel ocupacional concreto. En todos los casos las piezas corresponden a recipientes o contenedores, de carácter multifuncional, si bien su asociación a determinadas estructuras permite defender su empleo en actividades específicas que serán tratadas más adelante.

A pesar de que la ingente cantidad de material cerámico recuperado en el curso de las intervenciones arqueológicas realizadas en Ventosiños se halla todavía en proceso de estudio, es posible destacar varios aspectos que caracterizan la muestra $y$ contribuyen a definir el yacimiento. Se constata un predominio de las formas simples; vasos con tendencia cilíndrica o troncocónica, y cuencos suprahemiesféricos u ollas globulares, con perfiles simples en 's' levemente pronunciados. Esta simpleza en las formas, con algunas excepciones, contrasta con la variedad de tamaños
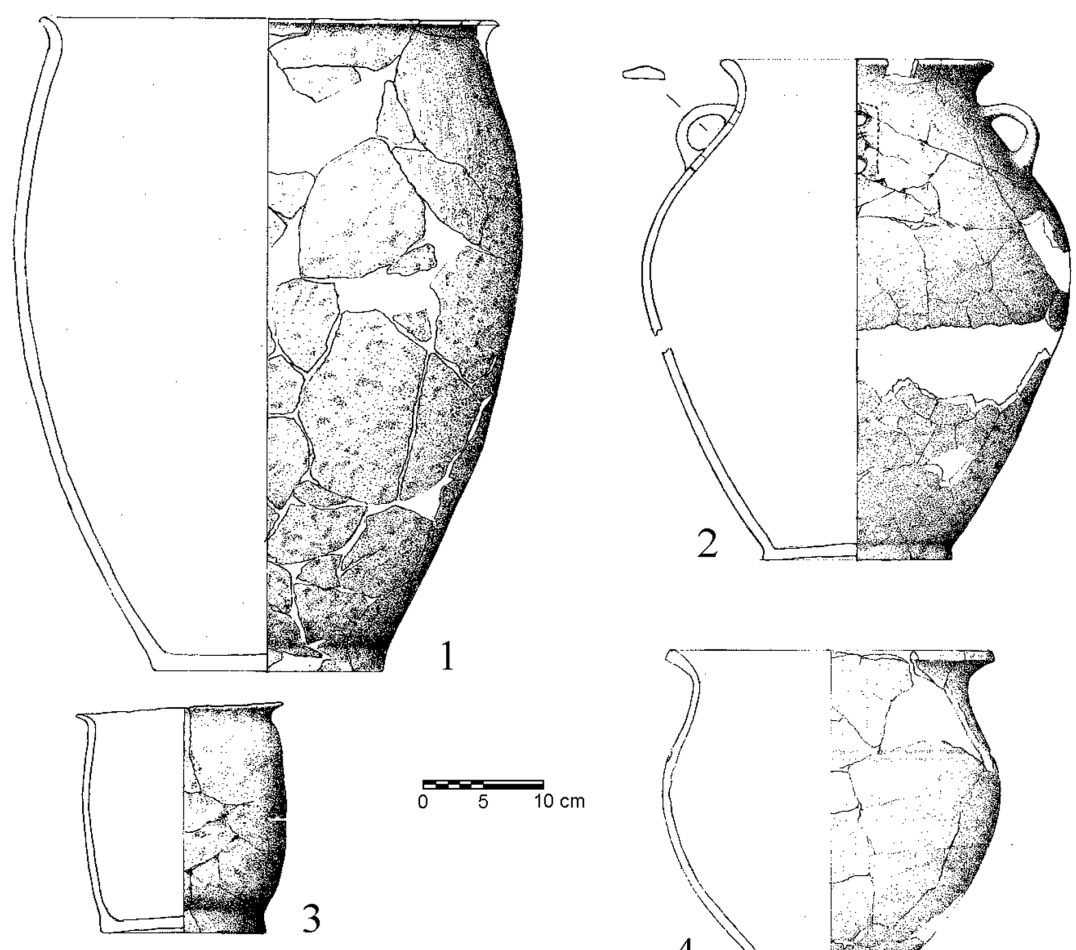
de las piezas, aún próximas espacial y contextualmente: desde los escasos $90 \mathrm{~mm}$ de altura hasta casi 600. Las piezas con asas constituyen una rareza, aunque no falta algún ejemplar, como un recipiente localizado en el relleno del enclos (Fig. 9 n. ${ }^{\circ}$ 2).

En las facturas puede observarse similar variedad: pastas más o menos depuradas, con predominio de desgrasantes graníticos -aunque la proporción de facturas con ausencia total de mica no es desdeńable-, y acabados por lo general bastante cuidados. Predomina el modelado manual y sólo

aquellas piezas de aspecto más evolucionado se levantaron con un torno bajo.

La mayor parte de los acabados son simples alisados, pero no faltan cepillados y pulidos casi satinados. Ya hemos indicado que el repertorio decorativo (Fig. 11) es escasísimo y, salvo raras excepciones, se reduce a motivos incisos, por lo general bandas, metopas o triángulos rellenos de líneas oblicuas que ocupan el tercio superior de la panza. Destaca además la presencia de motivos impresos - con estampilla y ruedecilla-, decoración localizada solo en el exterior. 

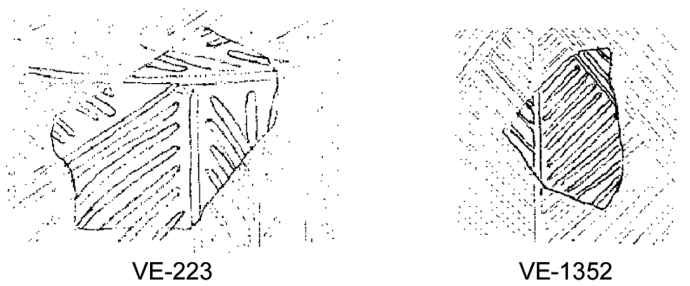

VE-1352

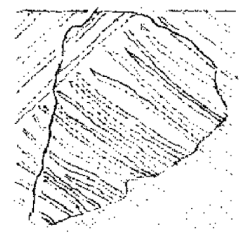

VE-205

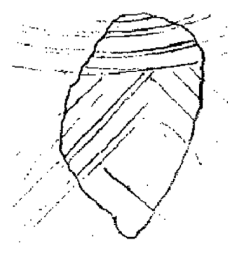

VE-202

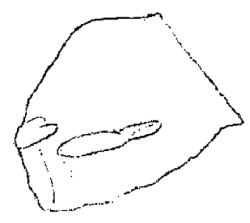

VE-220
VE-203

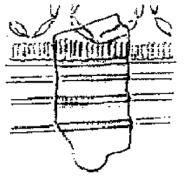

VE-1306

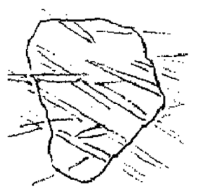

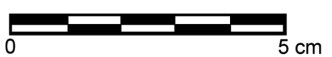

FIG. 10. Principales motivos decorativos documentados.

\subsection{Restos líticos}

Una revisión de conjunto de los objetos líticos permite establecer una serie de consideraciones de carácter general. En primer lugar se puede señalar que, salvo por la presencia de algún morfotipo concreto, los discos conforman un repertorio bastante genérico, aunque la proporción y distribución de los distintos elementos confieran cierta peculiaridad a este yacimiento.

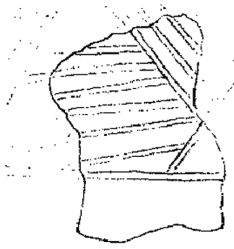

VE-425

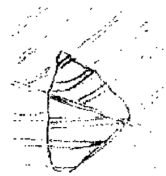

VE-206

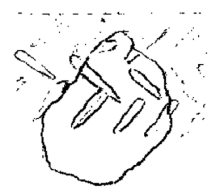

VE-204

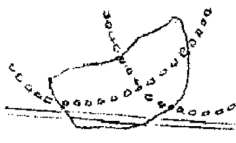

VE-214
Se localizaron 15 discos que, empleando el esquisto como soporte, presentan diámetros variables entre $21 \mathrm{~cm}$ y $11 \mathrm{~cm} \mathrm{y}$ grosor de $1 \mathrm{~cm}$. Los diámetros de las perforaciones oscilan entre 1,5 y $3 \mathrm{~cm}$. De 6 de ellos se conserva solamente una mitad y de 2 sólo un tercio, estando el resto completos. Las morfologías son ovales en 6 de estas piezas y de tendencia circular o circulares en 9 casos. En 13 de estos discos aparece una perforación central bitroncocónica, y existe además un caso con evidencias de hasta seis perforaciones. Todos los discos, exceptuando dos casos, se localizaron en las fosas exteriores o en el relleno del enclos. De los 2 restantes, uno se localizó en la superficie ocupacional y otro entre el sedimento de la construcción anular, durante la excavación del corte n. ${ }^{\circ} 2$.

La procedencia de las materias primas que sirvieron de soporte a la mayor parte de los objetos líticos documentados es local en la gran mayoría de las piezas. Destaca, no obstante, la presencia de tres objetos realizados en sílex, que evidencian el contacto con territorios distantes.

\subsection{Otros restos}

Se localizaron además tres elementos de carácter ornamental realizados en material vítreo: dos cuentas de collar y un colgante (Figs. 12 y 13). En la superficie ocupacional delimitada por la construcción anular se recuperó una cuenta subesférica, decorada con bandas onduladas por apliques de hilos claros, probablemente blancos, sobre un núcleo de color negro. La segunda cuenta, cilíndrica y decorada con plumeados en color amarillo, se localizó al E del anillo, también en la superficie ocupacional, sin vinculación con 

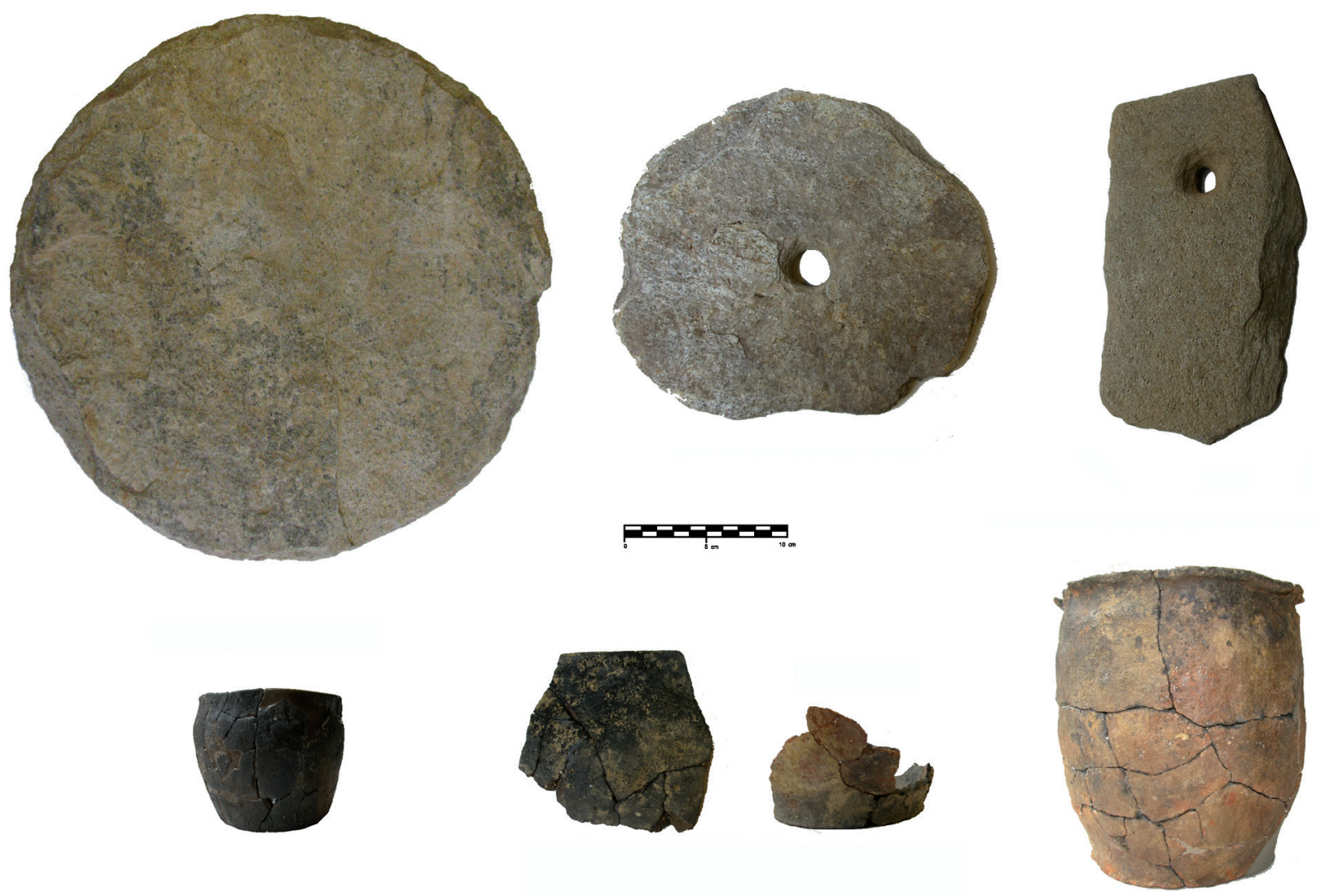

FIG. 11. Muestra de algunos materiales exhumados.

ninguna estructura concreta. Además se exhumó un colgante de vidrio (Fig. 13) en la parte superior del relleno del foso, durante la excavación del corte n. ${ }^{\circ} 2$. Se trata de un objeto formado por un haz de gruesos hilos doblados en lazo, de vidrio transparente de tonalidad azul verdosa.

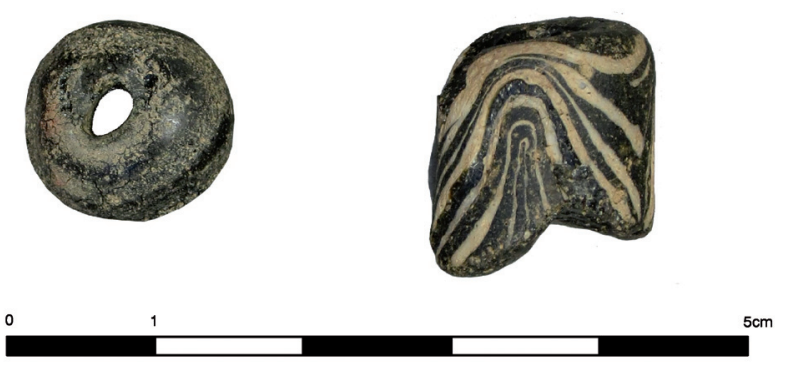

FIG. 12. Cuentas vitreas
Respecto al material metálico destaca la presencia de dos fragmentos de aspecto broncíneo, tal vez de fíbulas (Figs. 14 y 15): el primero, de forma amorcillada, se localizó en la superficie ocupacional delimitada por la construcción anular, ya parece evocar en una primera aproximación las fíbulas de
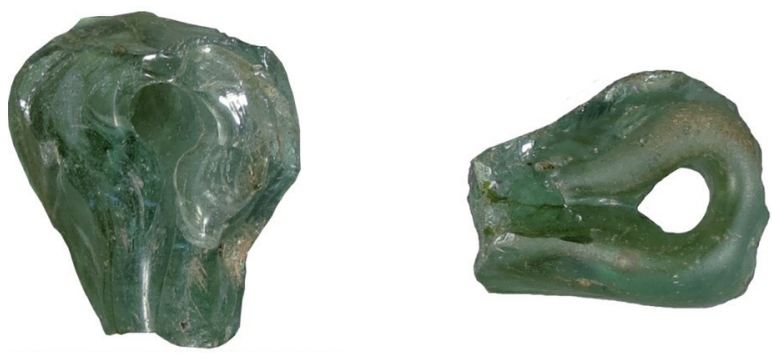

0

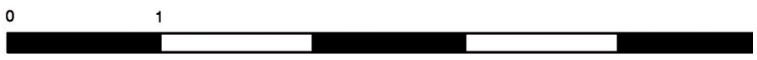

FIG. 13. Colgante de vidrio. 


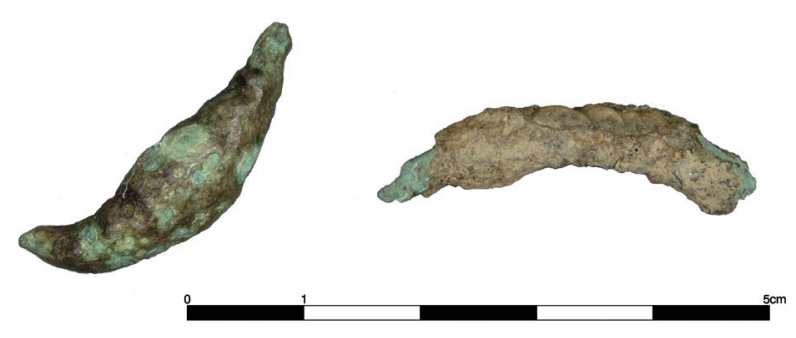

FIG. 14. Posibles fragmentos de fibula recuperados durante las intervenciones arqueológicas.

codo, mientras que el segundo, hallado en la superficie delimitada por el enclos, podría pertenecer a una de arco con decoración sogueada en el dorso. A ellos hay que sumar el ya mencionado hallazgo de la moneda de Isabel II y algunos fragmentos de escorias férricas.

\section{Cronología}

Se han realizado hasta la fecha cuatro dataciones, que han permitido obtener datos cronológicos para algunas estructuras significativas del conjunto. La primera muestra se tomó en un sedimento combustionado localizado en la base de la construcción anular, durante la realización del corte $n .{ }^{o} 2$ practicado en la estructura (Fig. 16). La segunda datación procede de una muestra de carbón recuperada en el sedimento que cubría la base de una fosa localizada en el interior de la construcción anular. Las dos últimas dataciones (Fig. 17) fueron extraídas a partir de sendas muestras de carbón que formaban parte de los sedimentos finales de las fosas exteriores I y II, ambos documentados bajo niveles sellados por losas de esquisto.

La cronología se situaría entre los ss. XI y IX a. C., a juzgar por las dataciones radiocarbónicas obtenidas (Fig. 17), período que se corresponde en el no peninsular con el Bronce final. Dado que las muestras se tomaron en el espacio interno de la construcción anular, en la base de la propia construcción anular y en dos de las fosas localizadas en el espacio externo -entre el enclos y la construcción anular-, parece posible establecer una relación cronológica entre estos ámbitos, apuntando a la ocupación de este espacio durante un mismo marco cronocultural.

Los materiales recuperados en el interior de las estructuras -principalmente las fosas exteriores y el enclos- no contradicen los resultados obtenidos en las
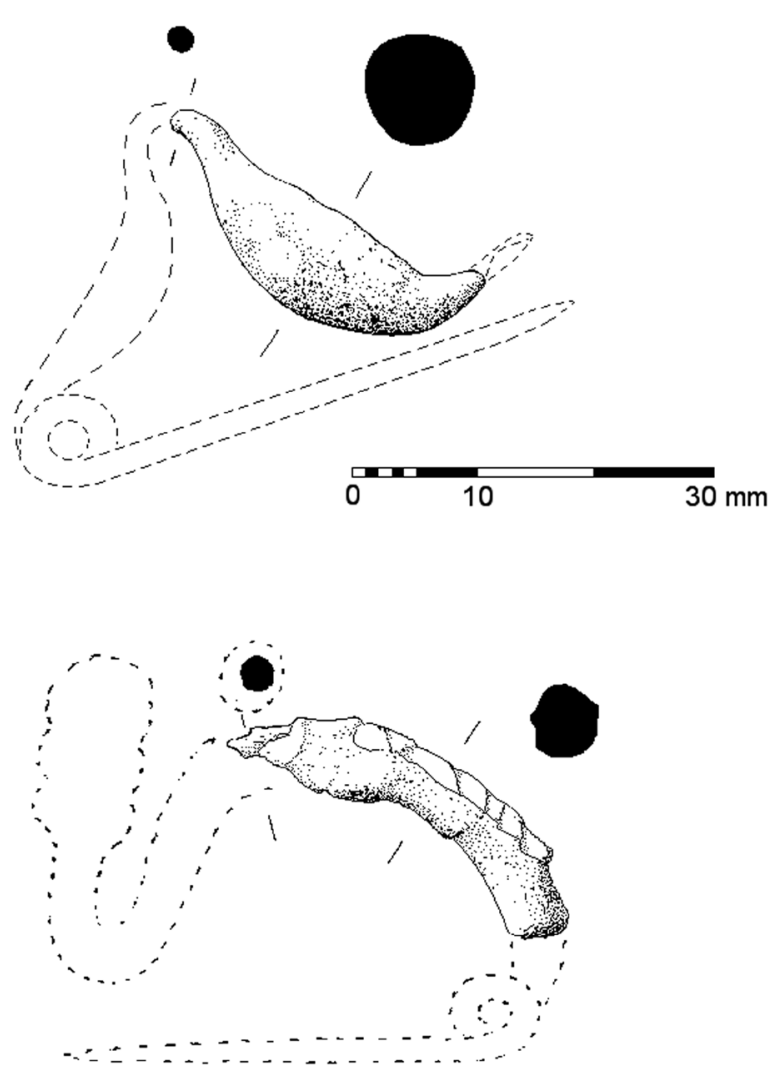

FIG. 15. Hipótesis reconstructiva de las fibulas.

dataciones. Entre los elementos cerámicos, los vasos troncocónicos aparecen ya en yacimientos del No en la primera mitad del segundo milenio (Nonat et al., 2015: 116-117, fig. 30), e incluso antes, ya que en el $\mathrm{N}$ de Portugal se documentan desde finales del III milenio a. C. (Bettencourt, 1999: vol. III, 1046).

Los discos líticos, perforados o no, tienen un marco temporal muy amplio en la prehistoria de Europa, e incluso trascienden estos límites. En el no de la Península Ibérica su presencia se extiende desde la época de desarrollo del fenómeno tumular hasta la época de los poblados fortificados 9 .

9 Discos similares aparecen entre el ajuar de la necrópolis tumular de Monte Perleo (Guitiriz, Lugo); A Abelleira (Roupar, Xermade, Lugo); en Dombate (A Coruña), se localizó un objeto con perforación bilateral inconclusa y forma toscamente cuadrangular; en Tecedeiras (Lalín, Pontevedra), se halló una placa de pizarra con perforación (Fábregas, 1991: 208-213). Otros ejemplos de discos perforados son recogidos por Vaquero 
Entre los elementos metálicos, la posible fíbula de codo - desconocida hasta ahora en el NO peninsular- podría corresponder al 'tipo Huelva', para el que se propone un arco cronológico entre los ss. XII y IX a. C. (Carrasco et al., 2012: 324-325), marco que encaja bien con las

\begin{tabular}{|l|c|c|l|}
\hline \multicolumn{1}{|c|}{ ESTRUCTURA } & UR & UE & \multicolumn{1}{|c|}{ INTERVALO DE CALIBRACIÓN } \\
\hline Construcción anular [CA] & L4 & 139 & Cal BC 1010-890 y Cal вC 880-850 \\
\hline Fosa interior VII [F.I.VII] & L6 & 91 & Cal BC 1050-910 \\
\hline Fosa exterior II [F.E.II] & I7 & 208 & Cal BC $910-810$ \\
\hline Fosa exterior I F.E.I] & J6 & 199 & Cal BC 1000-840 \\
\hline
\end{tabular}

FIG. 16. Tabla explicativa de las dataciones realizadas.

\section{dataciones radiocarbónicas ${ }^{10}$.}

Por otra parte, el estudio de

los restos arqueológicos recuperados en la superficie ocupacional -caracterizada por la fragmentación y dispersión de los materiales y con diferencias evidentes respecto a los materiales procedentes de las fosaspermite confirmar que el yacimiento continuó frecuentándose durante mucho tiempo, al menos hasta el s. IV a. C. A este momento pertenece la cerámica decorada con motivos impresos -con estampillas y ruedecilla-, que no aparece en contextos del No antes de los ss. V-IV a. C. Otros elementos que confirman la continuidad de la ocupación, a pesar de que su contexto estratigráfico es poco relevante, son el colgante y la cuenta cilíndrica plumeada, entre los vidrios ${ }^{11}$, y

y Vázquez (1993: 411-415). También se encuentran paralelos en el mundo megalítico del s peninsular, como en Los Millares, y se vinculan por lo general a monumentos calcolíticos, Para el disco multiperforado existen paralelos en el Castro de Penalba (Campo Lameiro, Pontevedra), en el de A Lanzada (Sanxenxo, Pontevedra) y en el de Calvor (Sarria, Lugo). Aunque no existe consenso en relación a la utilidad de los discos perforados, tradicionalmente se han relacionado con actividades de carácter textil o pesquero. En nuestra opinión, basándonos en los contextos en que fueron localizados y en la interpretación general que ofreceremos para el conjunto, no puede descartarse un uso de carácter cultual para este tipo de piezas.

10 Sobre la dispersión de las fíbulas de codo en la Península Ibérica $c f$. Argente (1994: 48-49).

11 Las cuentas originarias del Mediterráneo oriental tienen una amplia difusión ya desde finales del ir milenio a. C. La cuenta esférica con bandas alcanza la Europa templada -Francia y Ne peninsular- entre los s. X-IX a. C. (Rafel et al., 2008: 246, fig. 5.5). La cilíndrica plumeada aparece aquí desde los primeros contactos fenicios -sobre todo en los ss. VIII-VII a. C.-. Su presencia en el No peninsular es algo más tardía -VIIII a. C. - y es consecuencia de las relaciones vía marítima con fenicios o púnicos. Está constatada, no obstante, la presencia de cuentas de pasta vítrea en contextos precoloniales del $\mathrm{N}$ de Portugal, como por ejemplo en Santinha (Amares) y en Juliāo (Vila Verde), con dataciones calibradas de los ss. X-IX a. C. Por tanto, aunque el colgante procede de ámbitos orientales, desde donde se difunde a partir de los ss. viII-VII a. C. y en la la fíbula de arco con decoración sogueada, entre los metales ${ }^{12}$.

\section{Interpretación del conjunto}

Las intervenciones arqueológicas realizadas han permitido documentar tres espacios arqueológicos netamente diferenciados: por una parte, dos con una clara vinculación, la construcción anular con su espacio interno y la superficie que se extiende al $\mathrm{N}$ de la CA, cuyo límite septentrional es el enclos. La definición de ambos espacios se ha establecido por las diferencias de carácter arquitectónico existentes entre ambos espacios, por las características de la zona que delimitan y por el contenido de las estructuras documentadas en ambas superficies. Existen, por otra parte, similitudes entre ambos espacios, dado que en una fase avanzada los materiales exhumados en estas superficies presentan características similares. El tercer espacio se extiende al norte del enclos, superficie en la que los restos de estructuras y materiales disminuyen significativamente.

En las fosas localizadas al $\mathrm{N}$ de la construcción anular, y en el área delimitada por el enclos, el carácter habitacional está descartado, siendo la hipótesis más plausible el empleo de este espacio para el desarrollo

costa mediterránea peninsular se encuentra desde finales del s. VII, en el No, por el momento, aparece en contextos mucho más avanzados.

12 La decoración de los arcos en las fíbulas aparece principalmente en las denominadas 'tipo La Tene I', o más propiamente el denominado tipo 'trasmontano' en el NO; esta atribución llevaría a dataciones más avanzadas, ya que es imposible retraerlas de los ss. IV-III a. C. Para las dataciones de las fíbulas en la Meseta norte $c f$. Argente, 1987-1988: 151155, figs. 5.5 y 6.3. El 'tipo Sabroso' en el No puede remontarse a los ss. IV-III a. C., pero pervive en períodos posteriores, casi hasta el cambio de Era (Silva, 1986: 189-190, est. CIV, 7-10). 
DATACIONES VENTOSIÑOS

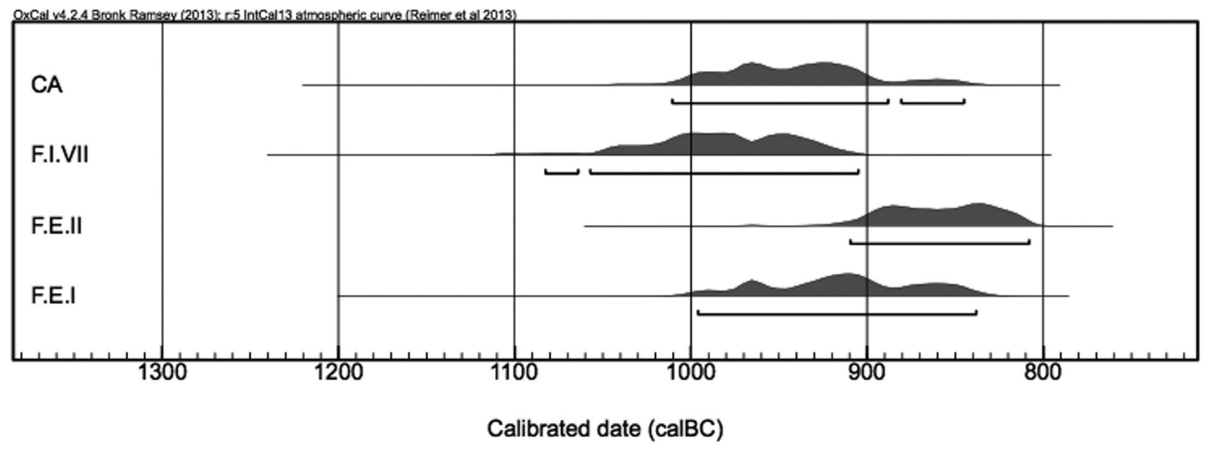

FIG. 17. Gráfico con representación de las dataciones realizadas.
En el caso de la construcción anular y su superficie interna, es necesario subrayar las dificultades interpretativas que presenta esta estructura, sin lugar a dudas la más singular de entre las documentadas durante las intervenciones arqueológicas realizadas en Ventosińos. Además de que se excavó sólo parcialmente, no hemos encontrado paralelos directos para esta estructura. En Barreiros

de actividades de carácter ceremonial. Esta interpretación se deduce a partir de la presencia de elementos líticos muy característicos, los discos perforados, para los que todo indica cada vez más que se trata de objetos de tipo cultual y no funcional, y que en buena parte están relacionados con el mundo funerario; y cerámicos, por ejemplo, los vasos troncocónicos, que parecen ser también característicos de contextos funerarios (Bettencourt, 2010: 144). La presencia de un recipiente de grandes dimensiones seccionado sagitalmente refuerza también la hipótesis enunciada, al igual que la deposición intencional de piezas enteras in situ, circunstancia que se da en las fosas exteriores, pero también en el enclos, elemento que actuó quizás como límite físico del espacio ceremonial ${ }^{13}$. Sin olvidar las concentraciones de fosfatos detectadas en las fosas en relación al depósito aluvial original, que no contradicen una interpretación funeraria para estas estructuras ${ }^{14}$. La ausencia de restos óseos, por otra parte también ausentes en muchos contextos funerarios del No, no permite realizar aseveraciones más concluyentes, y tampoco ir más allá, definiendo si se trataría de un rito de inhumación o incineración ${ }^{15}$.

13 Piggott (1981: 298) ofrece ejemplos en Francia de santuarios de forma alargada delimitados por enclos y datados en los ss. XI-X a. C.

14 Los análisis de los sedimentos extraídos de determinadas fosas y de algunos recipientes recuperados han sido realizados por A. Martínez Cortizas y R. Tallón Armada en la Univ. de Santiago de Compostela. Agradecemos a ambos las informaciones aportadas sobre los resultados, todavía inéditos.

15 Un doble enterramiento en una fosa con características similares a las documentadas en Ventosiños se halló en el Cerro
(Lugo) se localizó en 2006 un recinto de planta elípti$\mathrm{ca}$, de $35 \mathrm{~m}$ de diámetro y un parapeto de $2,5 \mathrm{~m}$ de altura en su parte más alta. Dicha estructura presentaba una entrada a modo de rampa en su parte nororiental y estaba circundada por una zanja. En el interior de dicha construcción no se localizaron estructuras arqueológicas, y los restos materiales recuperados fueron muy escasos, por lo que el director de los trabajos manifestaba la problemática de avanzar una funcionalidad para el conjunto y una cronología precisa, si bien se inclinaba por datar el yacimiento entre el Bronce final y el Hierro inicial (López García, 2006: 175-176). A pesar de la posible coincidencia cronológica, las afinidades entre la construcción anular de Ventosiños y la estructura localizada en Barreiros no van más allá de una cierta similitud en la planta; por otra parte, la escasez de restos materiales y de estructuras localizadas en este último no permiten la realización de análisis comparativos, por lo que, a falta de ulteriores investigaciones en Barreiros, la asociación entre ambos yacimientos es una quimera.

de la Cabeza (Ávila), con la salvedad de que en esta última se documentaron restos óseos de los difuntos y elementos metálicos formando parte del ajuar (Fabián y Blanco, 2010: 183-194). En la necrópolis de Vinha do Casão (Algarve, Portugal), se localizó un enterramiento en una fosa abierta en el suelo, similar al documentado en el Cortijo de Chichina (Sevilla). En la primera de estas fosas se halló una inhumación sin ajuar y en la segunda una inhumación acompańada de un vaso con cuatro mamelones en el borde datada en el Bronce final (Gomes, 1986). En San Román de la Hornija, se detectó una triple inhumación por debajo de un nivel de lajas, datada entre 1100 y 870 a. C.; encima del nivel de lajas, a 0,40 m de la boca de la fosa, se documentó además una fíbula de codo 'tipo Huelva' (Delibes de Castro, 1978: 225-250). 
También en la provincia de Lugo, en el municipio de $\mathrm{Vi-}$ llalba, se llevó a cabo en 2005 y 2006 la excavación del yacimiento de 'Os Castros'. En la actualidad no existe un estudio riguroso sobre este yacimiento, si bien en el informe de la intervención se señala una ocupación principal entre el Bronce final y las primeras fases del Hierro (ss. viII-v a. C.), extendiéndose hasta época romana ${ }^{16}$. En este yacimiento se documentaron estructuras de carácter funerario y habitacional, con claro predominio de las primeras. A pesar de su relación de proximidad con el hábitat castreño de Os Castros -circunstancia parangonable a la que se da con el Castro de Ventosiños en el caso analizado- no se localizó en Os Castros una construcción anular, sino que se documentó una serie de recintos sucesivos más o menos concéntricos, delimi-

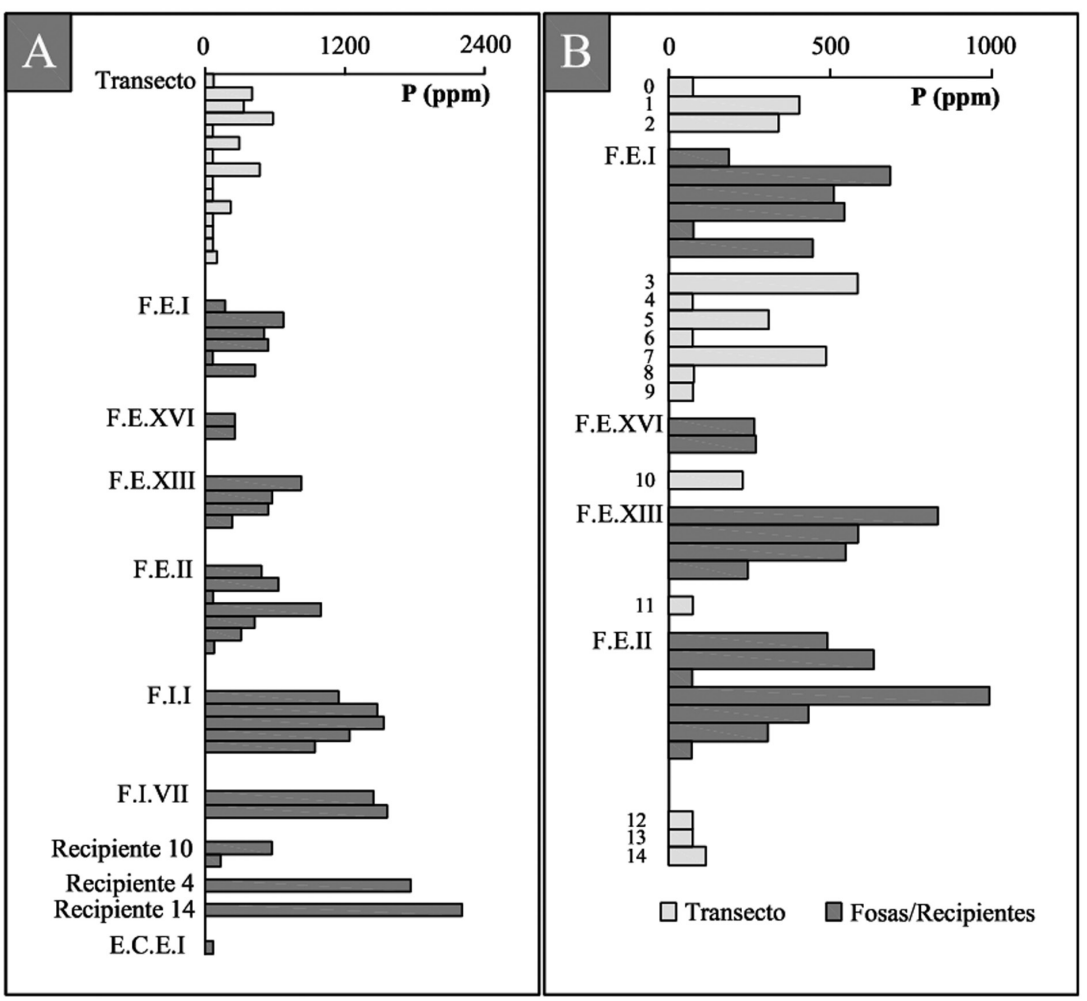

FIG. 18. Análisis de fósforo. tados por zanjas, ubicándose la mayor parte de las estructuras en el recinto original.

En el contexto europeo, existen en el mundo atlántico unas construcciones que presentan grandes similitudes con la estructura localizada en Ventosiños. Se trata de los denominados ringworks, construcciones datadas entre el 1100 y el 800 a. C. y documentadas en la parte oriental de Inglaterra. Se definen por su morfología anular y por la presencia de un parapeto exterior y un foso. Los diámetros de dichas estructuras oscilan entre los $40 \mathrm{~m}$ y los $120 \mathrm{~m}$ de diámetro. Los fosos alcanzan profundidades de hasta $4 \mathrm{~m}$ y los

16 Agradecemos a la directora de la intervención, M. P. Fernández Pintos, y a G. Meijide, arqueólogo de la Delegación Provincial de Lugo, su disponibilidad para mostrarnos la información disponible sobre dicha intervención. Los escasos datos disponibles sobre este yacimiento se incluyen en el informe valorativo de la intervención arqueológica realizada en Os Castros, actualmente depositado en la Dirección Xeral de Patrimonio Cultural de Galicia, en Santiago de Compostela (Fernández Pintos, M. P.: "Excavación en área en el yacimiento arqueológico de Os Castros". Informe Valorativo de 2006).

parapetos se elevan en ocasiones hasta $3 \mathrm{~m}$, y no es extraña la presencia de más de una entrada. En el interior aparecen compartimentaciones internas y numerosas fosas. El carácter excepcional de los materiales localizados en el interior ha llevado a algunos autores a sugerir que los ringworks eran centros de alto estatus (McOmish, 2011).

En el caso de Ventosiños, la utilización de la superficie delimitada por la construcción anular como espacio habitacional está descartada, siendo muy probable el aprovechamiento de su superficie interna para el desarrollo de ciertos ritos. La presencia de una serie de fosas con características estructurales y estratigráficas similares a las localizadas en el espacio exterior, el hallazgo de recipientes in situ y las variaciones en los niveles de fosfatos detectadas en el interior de estos y de las fosas apuntan de nuevo al desarrollo de actividades de carácter ceremonial, sin poder descartar la hipótesis funeraria.

La ocupación del yacimiento debió de iniciarse sobre el cambio de milenio, con la construcción de una serie de fosas de función ceremonial, tal vez 
funeraria. Una vez levantada la construcción anular, la actividad humana continuó, con la conciencia del carácter simbólico del lugar, durante un larguísimo período de tiempo, al menos hasta el s. IV. En esta dirección apunta la presencia de restos cerámicos -cuya fragmentación y dispersión contrasta con la presencia de piezas prácticamente enteras en el depósito de las fosas y en el interior del enclos- pertenecientes a formas evolucionadas, las decoraciones estampilladas, y ciertos elementos foráneos metálicos y de vidrio. Esta perdurabilidad en la ocupación puede ponerse quizás en relación con el Castro de Ventosiños, asentamiento fortificado no excavado, pero cuyas estructuras visibles apuntan a una fase plenamente desarrollada dentro de la Edad del Hierro, en la segunda mitad del primer milenio. Si para entonces la construcción anular y la superficie delimitada por el enclos siguieron manteniendo una función ritual, si este espacio actuó como referente simbólico, o lo hizo simplemente como una zona de actividad residual, es algo que no puede determinarse con los datos disponibles.

\section{Bibliografía}

Argente, J. L. (1986-1987): "Hacia una clasificación tipológica y cronológica de las fíbulas de la Edad de Hierro en la Meseta Norte", Zephyrus, xxxIX-XL, pp. 139-157.

Argente, J. L. (1994): Las fibulas de la Edad del Hierro en la Meseta oriental. Valoración tipológica, cronológica y cultural. Excavaciones Arqueológicas en España, 168. Madrid.

Bettencourt, A. (1999): A paisagem e o homem na bacia do Cávado durante o II e o I milénios AC. Braga: Univ. Minho

Bettencourt, A. (2010): "La Edad del Bronce en el Noroeste de la Península Ibérica: un análisis a partir de las prácticas funerarias", Trabajos de Prehistoria, 67 (1), pp. 139-173. http://dx.doi.org/10.3989/tp.2010.10034

Carrasco, J.; Pachón, J. A.; Montero-Ruiz, I. y Gámiz, J. (2012): “Fíbulas de codo 'tipo Huelva' en la Península
Ibérica: nuevos datos y comentarios historiográficos", Trabajos de Prehistoria, 69 (2), pp 310-331. http://dx.doi.org/10.3989/tp.2012.12094

Delibes de Castro, G. (1978): "Inhumación triple de facies Cogotas I en San Román de la Hornija”, Trabajos de Prehistoria, 35 (1), pp. 225-250.

Fabián, J. F. y Blanco, A. (2010): "El enterramiento en fosa del Cerro de la Cabeza (Ávila). La cuestión funeraria en el Bronce Final/Hierro i en el suroeste de la Meseta norte”. En Bueno, P.; Gilman, A.; Martín Morales, C. y Sánchez-Palencia, F. J.: Arqueología, Sociedad, Territorio y Paisaje. Bibliotheca Praehistorica Hispana, 28. Madrid: CSIC, pp. 183-194.

Fábregas, R. (1991): Megalitismo del Noroeste de la Península Ibérica. Tipologia y secuencia de los materiales líticos. Madrid.

Gomes, M. V.; Gomes, R. V.; Beirão, C. M. M. y Matos, J. L. (1986): A Necropole da Vinha do Casão (Vilamoura, Algarve) no contexto da Idade do Bronze do Sudoeste Peninsular. Trabalhos de Arqueologia, 2. Lisboa: IPpC.

López García, J. C. (2006): “Escavación en área do xacemento da Roda, Barreiros (Lugo)". En Actuacións arqueolóxicas ano 2006. Santiago de Compostela: Xunta de Galicia, pp. 175-176.

McOmish, D. (2011): Introductions to Heritage Assets: Enclosed Prehistoric Settlements. Swindon: English Heritage.

Nonat, L.; Vázquez, P. y Prieto, M. P. (2015): El vaso de largo bordo horizontal: un trazador cultural del Noroeste de la Península Ibérica en el II milenio BC. BAR, Intern. Ser., 2699. Oxford: Archaeopress.

Piggott, S. (1981 [1965]): A Europa antiga. Do inicio da agricultura à antiguidade clásica. Porto: edic. Fundación Calouste Gulbenkian.

Rafel, N.; Vives-Ferrándiz, J.; Armada, X. L. y Graells, R. (2008): "Las comunidades de la Edad del Bronce entre el Empurdá y el Segura: espacio y tiempo de los intercambios”. En Celestino, S.; Rafel, N. y Armada, X. L. (eds.): Contacto cultural entre el Mediterráneo y el Atlántico (siglos XII-VII ane). Madrid: CsIC, pp. 239-271.

Silva, A. C. F. (1986): A Cultura Castreja no Noroeste de Portugal. Porto: Univ. Porto.

Vaquero, J. y Vázquez, S. (1993): “Túmulos tardíos en el NW. RB 1: piezas". En Actas XXII Congreso Nacional de Arqueología. Vigo, vol. 1, pp. 411-415. 